\title{
Activity-Based Protein Profiling Identifies $\alpha$-Ketoamides as Inhibitors for Phospholipase A2 Group XVI
}

Juan Zhou, ${ }^{\dagger} \odot$ Elliot D. Mock, ${ }^{\dagger}$ Andrea Martella, ${ }^{\dagger \odot}$ Vasudev Kantae, ${ }^{\ddagger}, \oplus$ Xinyu Di, Lindsey Burggraaff, ${ }^{\S}$ Marc P. Baggelaar, ${ }^{\dagger}$ Karol Al-Ayed, ${ }^{\dagger}$ Alexander Bakker, ${ }^{\dagger}$ Bogdan I. Florea, ${ }^{\|}$ Sebastian H. Grimm, ${ }^{\dagger \oplus}$ Hans den Dulk, ${ }^{\dagger}$ Chun T. Li, ${ }^{\dagger}$ Laura Mulder, ${ }^{\dagger}$ Herman S. Overkleeft, ${ }^{\dagger}$ Thomas Hankemeier, ${ }^{\ddagger}$ Gerard J. P. van Westen, ${ }^{\S}$ and Mario van der Stelt ${ }^{*}, \oplus$

${ }^{\dagger}$ Department of Molecular Physiology, Leiden Institute of Chemistry, Leiden University, Leiden, The Netherlands

${ }^{\ddagger}$ Department of Analytical BioSciences and Metabolomics, Leiden Academic Centre for Drug Research, Leiden University, Leiden, The Netherlands

${ }^{\S}$ Department of Computational Drug Discovery, Leiden Academic Centre for Drug Research, Leiden University, Leiden, The Netherlands

"Department of Bio-Organic Synthesis, Leiden Institute of Chemistry, Leiden University, Leiden, The Netherlands

\section{Supporting Information}

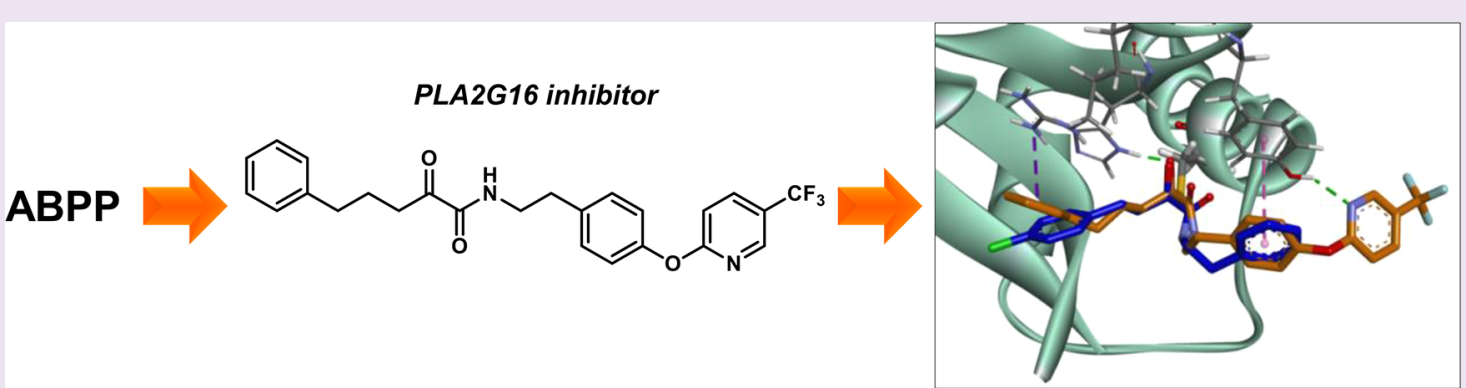

ABSTRACT: Phospholipase A2, group XVI (PLA2G16) is a thiol hydrolase from the HRASLS family that regulates lipolysis in adipose tissue and has been identified as a host factor enabling the cellular entry of picornaviruses. Chemical tools are essential to visualize and control PLA2G16 activity, but they have not been reported to date. Here, we show that MB064, which is a fluorescent lipase probe, also labels recombinant and endogenously expressed PLA2G16. Competitive activity-based protein profiling (ABPP) using MB064 enabled the discovery of $\alpha$-ketoamides as the first selective PLA2G16 inhibitors. LEI110 was identified as a potent PLA2G16 inhibitor $\left(K_{i}=20 \mathrm{nM}\right)$ that reduces cellular arachidonic acid levels and oleic acid-induced lipolysis in human HepG2 cells. Gel-based ABPP and chemical proteomics showed that LEI110 is a selective pan-inhibitor of the HRASLS family of thiol hydrolases (i.e., PLA2G16, HRASLS2, RARRES3 and iNAT). Molecular dynamic simulations of LEI110 in the reported crystal structure of PLA2G16 provided insight in the potential ligand-protein interactions to explain its binding mode. In conclusion, we have developed the first selective inhibitor that can be used to study the cellular role of PLA2G16.

$\mathrm{P}$ hospholipase A2, group XVI (PLA2G16), was first isolated in murine fibroblasts as a product of the HRASLS gene family, which also includes the phospholipase/ acyltransferases, namely, phospholipid metabolizing enzyme A-C1 (A-C1), HRAS-like suppressor 2 (HRASLS2), Retinoid acid receptor responder protein 3 (RARRES3), and $\mathrm{Ca}^{2+}$. independent $N$-acyltransferase (iNAT). ${ }^{1-3}$ PLA2G16 is an intercellular, single-pass transmembrane thiol hydrolase with a molecular weight of $18 \mathrm{kDa}$ that predominantly hydrolyzes the sn-2 fatty acyl chain of phosphatidylcholine. ${ }^{4,5}$ PLA2G16 has a papain-fold motive consisting of three $\alpha$-helices and five antiparallel $\beta$-sheets organized in a circular permutation and a conserved catalytic triad consisting of Cys113, His23, and His35, as determined by X-ray crystallography (PDB code: 4DOT) and site-directed mutagenesis studies. ${ }^{6-9}$
PLA2G16 is found in various cell lines (e.g., HepG2) ${ }^{10,11}$ and adipose tissue. ${ }^{12,13}$ Its expression is induced during adipocyte differentation. ${ }^{14,15}$ PLA2G16 regulates lipolysis, and its genetic ablation prevented obesity in mice induced by a high fat diet or leptin deficiency. ${ }^{16}$ Recently, PLA2G16 was identified as a host factor for picornaviruses, which cause the common cold, by facilitating viral genome translocation and preventing clearance of the virus in host cells. ${ }^{17,18}$ Taken together, these genetic studies highlight the therapeutic potential of PLA2G16. However, to date, there are no

Received: October 31, 2018

Accepted: January 8, 2019

Published: January 8, 2019 
A

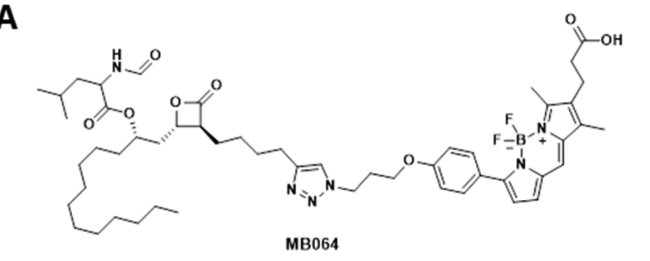

C
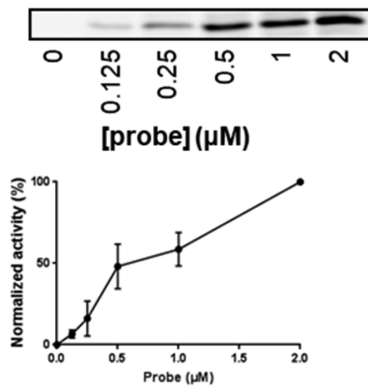

B
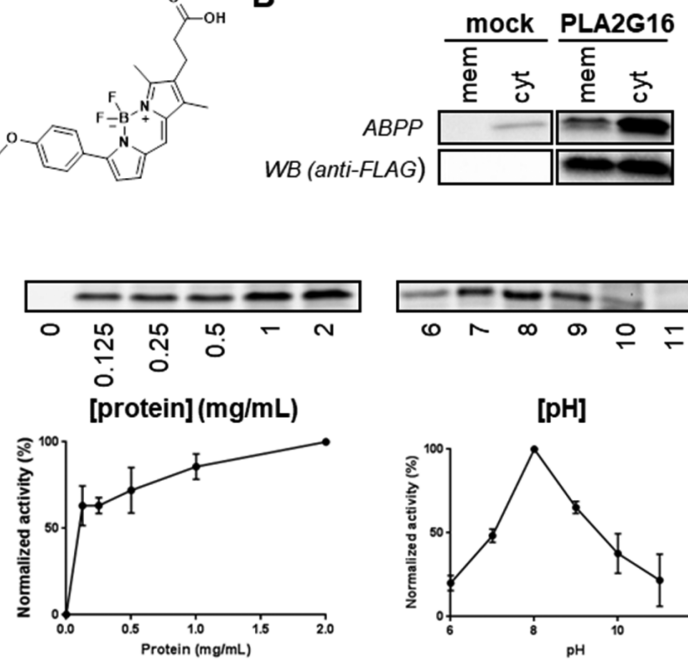
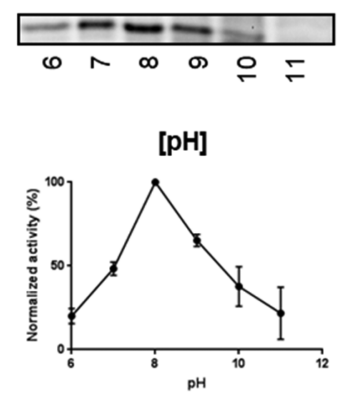

D

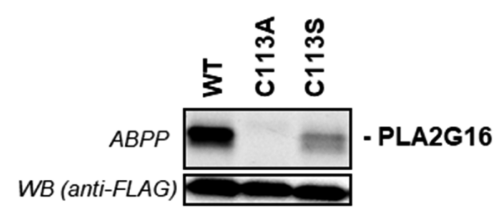

E

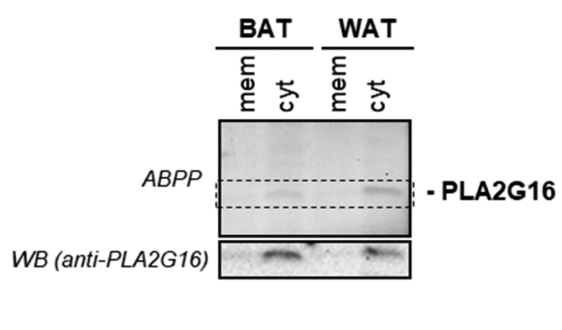

Figure 1. Characterization of MB064 as an ABP for PLA2G16. (A) Chemical structure of probe MB064. (B) ABPP using MB064 with PLA2G16 membrane (mem) or cytosol (cyt) proteome $\left(1 \mathrm{mg} \mathrm{mL}^{-1}\right)$ transiently expressed in HEK293T cells and Western blot of the ABPP gel using an anti-FLAG antibody. (C) ABPP condition optimization for human PLA2G16 cytosol proteome using MB064. For the probe concentration test, $0.5 \mathrm{mg} \mathrm{mL}^{-1}$ protein lysate was used. For the protein concentration test, probe of $500 \mathrm{nM}$ was used. (D) ABPP using MB064 with different hPLA2G16 constructs, and Western blot of the ABPP gel using an anti-FLAG antibody. (E) Labeling of endogenous PLA2G16 in WAT and BAT cytosol proteome by MB064, and Western blot of the ABPP gel using an anti-PLA2G16 antibody (full gels are given in the SI).

PLA2G16 inhibitors reported that can be used as pharmacological tools to validate PLA2G16 as a therapeutic target.

Activity-based protein profiling (ABPP) is a powerful chemical biological technique that allows efficient lead discovery studies by assessing inhibitor activity and selectivity in complex, native proteomes. ${ }^{19,20}$ ABPP makes use of chemical probes that covalently react with the catalytic amino acid in an activity-dependent manner. The activity-based probe $(\mathrm{ABP})$ contains a warhead linked to a fluorophore or biotin reporter tag for fluorescent- or mass-spectrometrybased detection, respectively. Currently, no ABPs have been reported for PLA2G16 that could enable inhibitor discovery.

Previously, we have developed and applied the $\beta$-lactonebased probe (MB064) as a broad-spectrum probe for the identification of highly potent and selective diacylglycerol lipase inhibitors. ${ }^{21,22}$ In addition, MB064 was instrumental in the discovery of the off-target profile of the fatty acid amide hydrolase inhibitor BIA $10-2474$ that caused the death of a volunteer in a clinical phase 1 study. ${ }^{23}$ The $\beta$-lactone is a warhead that covalently reacts with the catalytic serine in many serine hydrolases, forming an acyl-enzyme intermediate. Interestingly, MB064 has also been reported to form thioester bonds with the catalytic cysteine of various enzymes. ${ }^{24}$ Here, we report that MB064 labels PLA2G16 in an activitydependent manner and is able to visualize endogenous PLA2G16 in adipose tissue. Screening of a focused lipase inhibitor library using ABPP and subsequent hit optimization resulted in the identification of $\alpha$-ketoamide LEI110 as a selective PLA2G16 inhibitor that reduces cellular arachidonic acid levels and oleic acid-induced lipolysis in human HepG2 cells.

Previously, we have developed MB064 as an ABP for diacylglycerol lipase- $\alpha / \beta$ (structure shown in Figure 1A). ${ }^{21}$ MB064 could cross-react with many enzymes that employed a serine or cysteine as a nucleophile, ${ }^{22}$ thereby making it an excellent chemical tool to profile inhibitor activity and selectivity on endogenously expressed enzymes in various biological samples. To test whether MB064 could also label PLA2G16, we incubated MB064 with proteomes of transiently overexpressed human PLA2G16-FLAG in human embryonic kidney 293 T (HEK293T) cells, followed by sodium dodecyl sulfate polyacrylamide gel electrophoresis (SDS-PAGE) and fluorescent scanning. A fluorescent band was observed at the expected MW, which overlapped with a band visualized by the FLAG-tag antibody and was absent in mock-transfected cells (Figure 1B). The labeling was probeand protein-concentration-dependent (Figure 1C) and was optimal at $\mathrm{pH} 8$, which is consistent with previously reported $\mathrm{pH}$ dependency of PLA2G16. ${ }^{14,25}$ Site-directed mutagenesis of the catalytic Cys113 into alanine or serine abolished or significantly reduced labeling, respectively, whereas its expression was not substantially altered as witnessed by FLAG-tag antibodies (Figure 1D). Of note, MB064 was also able to cross-react with HRASLS2, RARRES3, and iNAT (Figure S2 in the Supporting Information (SI)). Finally, we tested whether MB064 could also label endogenously expressed PLA2G16. To this end, we incubated MB064 with freshly isolated mouse white adipose tissue (WAT) and brown adipose tissue (BAT) proteomes. A fluorescent band was visualized at the expected MW, which also overlapped with a band observed by PLA2G16 antibodies (Figure 1E). Taken together, these results demonstrate that MB064 can efficiently label active human PLA2G16 via a covalent bond with Cys 113 and visualizes native mouse PLA2G16 in brown and white adipose tissue.

Having identified MB064 as a suitable chemical probe targeting PLA2G16, we set out to screen a small focused library of 50 lipase inhibitors at $10 \mu \mathrm{M}$ in a competitive ABPP format. This led to discovery of 4-(4-chlorophenyl)-2oxo- $N$-phenethylbutan-amide, an $\alpha$-ketoamide (compound 1) as a hit that almost completely abolished PLA2G16 labeling at $10 \mu \mathrm{M}$ (Figure 2A). 
A
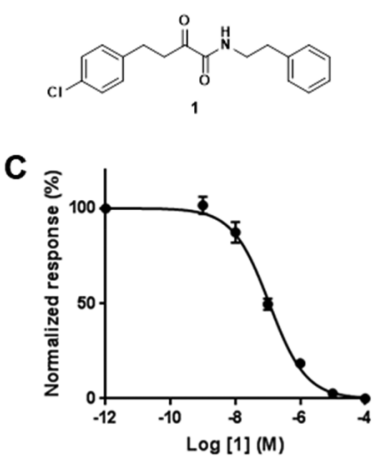

B

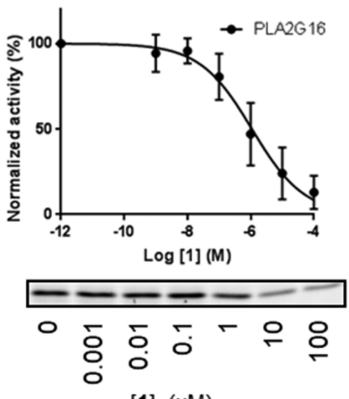

[1] $(\mu \mathrm{M})$

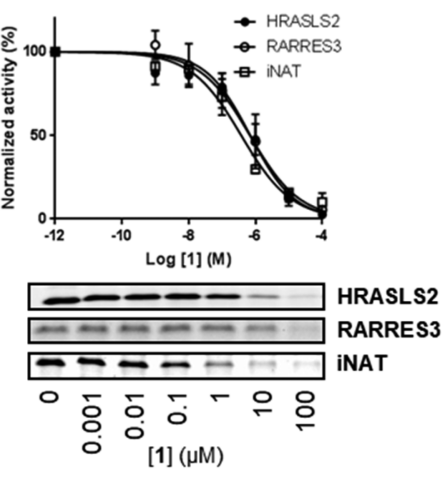

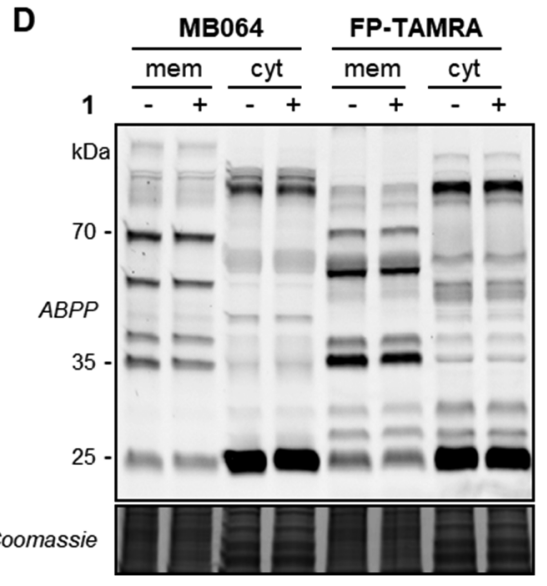

Figure 2. Discovery and biochemical characterization of compound 1. (A) Chemical structure of 1. (B) Dose-response curves for 1 on PLA2G16 (left) and other HRASLS members, HRASLS2, RARRES3, and iNAT (right) measured by competitive ABPP using cytosol proteome prepared from transfected HEK293T cells with probe MB064. Under the curves are the corresponding ABPP gels: concentration-dependent inhibition of 1 against different proteins $(n=3)$. (C) Dose-response curve of 1 for PLA2G16 (cytosol proteome prepared from PLA2G16 overexpressing HEK293T cells) with the PC-A2 fluorescent substrate assay $(n=3)$. (D) Selectivity of 1 against MB064 and FP-TAMRA in mouse brain membrane (mem) and cytosol (cyt) proteome. Coomassie was used as a protein loading control. Minus sign $(-)$ indicates control (with DMSO), plus sign (+) indicates with 1 at $10 \mu \mathrm{M}$.

Compound $\mathbf{1}$ was resynthesized using previously reported procedures (see the Materials and Methods section) and tested in a concentration-response ABPP assay. Compound 1 displayed a half-maximum inhibitory concentration $\left(\mathrm{pIC}_{50}\right.$ \pm SEM) of $6.0 \pm 0.1(n=3)$ (Figure $2 \mathrm{~B})$. Furthermore, it demonstrated similar activity on the other proteins of the HRASLS-gene family (HRASLS2, RARRES3, and iNAT) with a $\mathrm{pIC}_{50}$ in the range of 6.0-6.2 (Figure 3B, Table 1). Next, we confirmed the inhibitory activity of compound $\mathbf{1}$ in a previously reported orthogonal biochemical fluorescence assay that uses the Green/Red Bodipy PC-A2 as a surrogate substrate (with a $K_{\mathrm{M}}$ of $7.8 \pm 2.2 \mu \mathrm{M}$ ) and cytosol PLA2G16 fraction of HEK293T cells overexpressing human PLA2G16. ${ }^{8}$ Compound 1 displayed a $K_{i}$ value of $84 \mathrm{nM}$ (95\% confidence interval CI: 72-96 nM) (Figure 2C). $\alpha$-Ketoamides have previously been reported to inhibit serine hydrolases expressed in the brain. ${ }^{26-29}$ To determine the selectivity of compound 1 on endogenously expressed serine hydrolases, we performed a competitive ABPP experiment in mouse brain proteomes using the broad-spectrum serine hydrolase ABPs, fluorophosphonate (FP)-TAMRA, and MB064. Compound $1(10 \mu \mathrm{M})$ did not reduce the labeling of any proteins in mouse brain targeted by FP-TAMRA or MB064 (Figure 2D). Taken together, these results indicate that $\alpha$-ketoamide $\mathbf{1}$ is a selective inhibitor of PLA2G16 and its family members.

To improve the inhibitory activity of $\mathbf{1}$, a hit optimization program was initiated in which 64 analogues were synthesized (data not shown). This resulted in the discovery of 2-oxo-5-phenyl- $\mathrm{N}$-(4-((5-(trifluoromethyl)pyridin-2-yl)oxy)-phenethyl)pentanamide (LEI110) as a PLA2G16 inhibitor with a 10-fold increased potency $\left(\mathrm{pIC}_{50}=7.0 \pm\right.$ 0.1 ), compared to compound $\mathbf{1}$ in the ABPP-assay (Figures $3 \mathrm{~A}$ and $3 \mathrm{~B}$ ). LEI110 was also active on HRASLS2, RARRES3, and iNAT (Figure 3B, Table 1). LEI110 demonstrated a $K_{i}$ value of $20 \mathrm{nM}$ (95\% CI: 17-24 nM) in the biochemical PLA2G16 assay (Figure 3C) and was selective over brain serine hydrolases as determined with a gel-based ABPP assay (Figure S7 in the SI). PLA2G16 is endogenously expressed in brown and white adipose tissue, and its activity could be visualized by MB064 (Figure 3D); therefore, we tested whether compound 1 and LEI110 were able to block PLA2G16 activity in adipose tissue. Indeed, both compounds completely abolished labeling of native PLA2G16 by MB064, whereas the labeling of other proteins in brown and white adipose tissue was not affected (Figure 3D). The selectivity of LEI110 in adipose tissue was confirmed in a chemical proteomics assay using MB108 (THL-biotin) and FP-biotin, respectively (Figures 3E and 3F, respectively; see structures in Figure $S 1$ in the Supporting Information). ${ }^{30}$ Based on its activity and selectivity profile, we decided to test LEI110 in a cellular assay. To this end, we transfected human PLA2G16 in U2OS cells and incubated them with vehicle (DMSO) or LEI110 $(10 \mu \mathrm{M})$ under serum-free conditions. This led to a time-dependent increase in arachidonic acid, a product of PLA2G16, as determined by targeted lipidomics, which could be almost completely abolished by LEI110 (Figure 3G). Taken together, these results indicate that LEI110 is a potent, selective, and cellpermeable PLA2G16 inhibitor.

Table 1. $\mathrm{pIC}_{50} \pm \operatorname{SEM}(n=3)$ of Compound 1 and LEI110 against HRASLS Protein Family Members from the ABPP Assay

\begin{tabular}{lcccc} 
& \multicolumn{4}{c}{ pIC $_{50} \pm$ SEM } \\
\cline { 2 - 5 } compound & PLA2G16 & HRASLS2 & RARRES3 & iNAT \\
\cline { 2 - 5 } 1 & $6.0 \pm 0.1$ & $6.2 \pm 0.1$ & $6.2 \pm 0.1$ & $6.4 \pm 0.1$ \\
LEI110 & $7.0 \pm 0.1$ & $6.8 \pm 0.1$ & $6.8 \pm 0.1$ & $7.6 \pm 0.1$
\end{tabular}

Genetic studies have previously demonstrated that PLA2G16 regulates lipolysis; ${ }^{16,31}$ therefore, we tested whether LEI110 modulates lipolysis in human hepatocytes. Stimulation of HepG2 cells with oleic acid induces steatosis that eventually results in lipid droplet formation, as visualized by Adipored, and is a widely used in vitro model to study fatty liver diseases. ${ }^{32,33}$ Since PLA2G16 activity could not be observed in HepG2 cells using our ABPP method, probably due to its low abundance, we confirmed PLA2G16 mRNA expression in HepG2 cells via qPCR (Table S2 in the SI). Of 
A

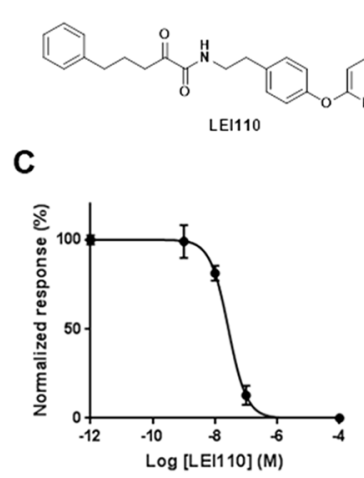

B

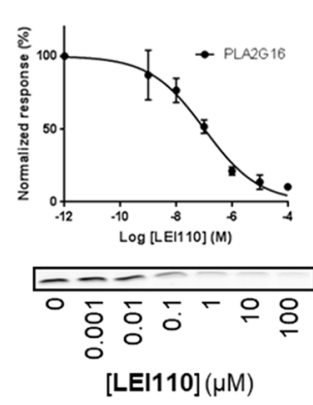

E

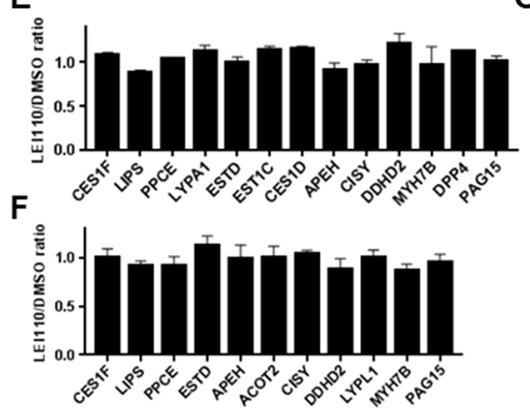

G

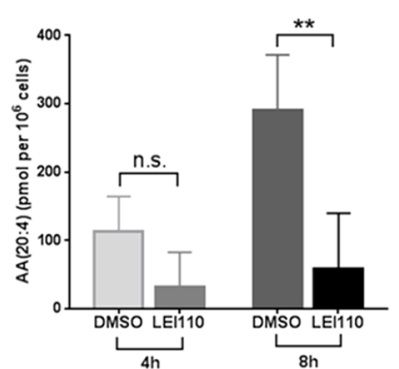

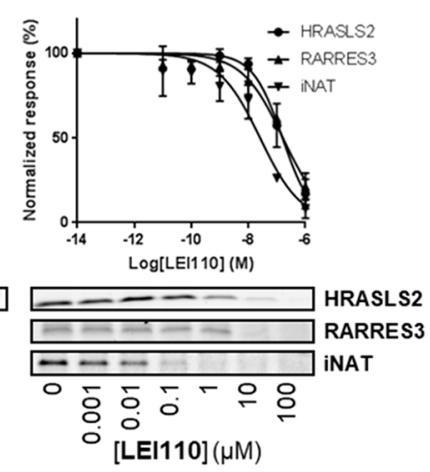

D

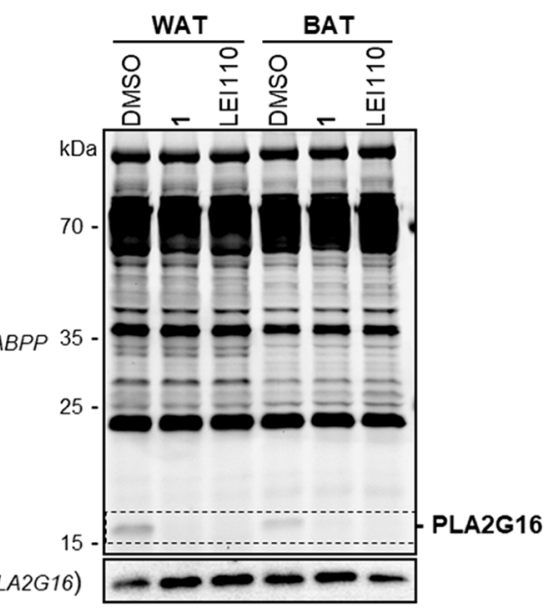

Figure 3. Biochemical characterization of LEI110. (A) Chemical structure of LEI110. (B) Dose-response curves of LEI110 against PLA2G16 and other HRASLS family members with probe MB064. (C) Dose-response curve of LEI110 for PLA2G16 with the PC-A2 fluorescent substrate assay. (D) Competitive ABPP of compound 1 and LEI110 against endogenous PLA2G16, using MB064 in the cytosol proteome of mouse WAT and BAT and Western blot of the ABPP gel using an anti-PLA2G16 antibody. Both inhibitors could compete the activity of PLA2G16 at $10 \mu \mathrm{M}$. (E) MB108 and FP-biotin based chemoproteomic analysis of serine hydrolase activities in the mouse WAT cytosol proteome treated with LEI110 $(10 \mu \mathrm{M})$. (F) MB108 and FP-biotin based chemoproteomic analysis of serine hydrolase activities in the mouse BAT cytosol proteome treated with LEI110 $(10 \mu \mathrm{M})$. (G) In situ treatment of U2OS cells overexpressing PLA2G16 with LEI110 (10 $\mu \mathrm{M}, 4$ or $8 \mathrm{~h}$ ) reduced arachidonic acid (AA) levels that were induced by PLA2G16. (H) In situ treatment of HepG2 cells with LEI110 (10 $\mu$ M, $24 \mathrm{~h}$ ) reversed the lipid accumulation in the cells induced by oleic acid (OA, $100 \mu \mathrm{M}, 24 \mathrm{~h}$ ). (I) Structure-guided modeling of 1 and LEI110. Compounds 1 (blue) and LEI110 (orange) in complex with PLA2G16, covalently bound to Cys113. Green dotted lines represent a hydrogen bond, pink and purple represent $\pi$-interactions. Data represent mean values \pm SEM for at least three replicates. [Legend: $*, p<0.05$; $* *, p<$ 0.01 ; ***, $p<0.001$ using the Student's $t$-test.]

note, very low mRNA levels for the other HRASLS-gene family members were found. In addition, the selectivity of LEI110 in HepG2 cells was confirmed in a chemical proteomics assay with MB108 and FP-biotin (Figure S8 in the SI). Next, we incubated HepG2 cells with LEI110 (10 $\mu \mathrm{M}$ ) before oleic acid treatment and observed a reduction in lipid droplet formation, which indicates that LEI110 modulates lipolysis (Figure $3 \mathrm{H}$ ). This is consistent with previous reports showing that PLA2G16 modulates lipid metabolism in HepG2 cells or adipocytes. ${ }^{16,31}$

Finally, to gain insight in the molecular interactions of $\alpha$ ketoamides with PLA2G16, LEI110 and 1 were docked in a PLA2G16 crystal structure (PDB: 4DOT). ${ }^{6}$ We envisioned that the electrophilic ketone of LEI110 and 1 could act through a reversible covalent mechanism with the active site Cys113 forming a hemithioacetal adduct, similar to other reported $\alpha$-ketoamide inhibitors. ${ }^{34}$ LEI110 and $\mathbf{1}$ were thus covalently attached to Cys113 in the enzyme and a molecular dynamics simulation was performed (Figure 3I). Hydrogen bonding of the oxyanion with His 23 was observed in both cases, as well as $\pi-\pi$ stacking with Tyr21. The extension of the ketone alkyl chain by one methylene allows for a more optimal $\pi$-cation interaction with Arg18 for LEI110, compared to 1. Furthermore, the introduction of the pyridyl moiety in LEI110 enables an additional hydrogen bond with the Tyr21-OH. These docking results provide a potential explanation for the 10-fold increase in activity seen for LEI110.

In conclusion, we have applied competitive $\mathrm{ABPP}$ using MB064 to discover $\alpha$-ketoamides as the first selective PLA2G16 inhibitors. LEI110 was identified as a potent PLA2G16 inhibitor $\left(K_{i}=20 \mathrm{nM}\right)$ that reduces cellular arachidonic acid levels in PLA2G16-overexpressing U2OS cells and oleic acid-induced steatosis in human HepG2 cells. Gel-based ABPP and chemical proteomics showed that LEI110 is a selective pan-inhibitor of the HRASLS-family of thiol hydrolases (i.e., HRASLS2, RARRES3, and iNAT). Molecular dynamic simulations of LEI110 in the reported crystal structure of PLA2G16 provided insight in the potential ligand-protein interactions to explain its binding mode. $\alpha$-Ketoamides have previously been employed as warheads for the inhibition of hydrolases ${ }^{35-37}$ and are incorporated in marketed drugs for the treatment of the viral infection with hepatitis C (e.g., boceprevir); ${ }^{38,39}$ therefore, it is anticipated that LEI110 constitutes an excellent starting point for the structure-based drug development of novel molecular therapies for obesity and/or the common cold. 


\section{METHODS}

All methods are described in the Supporting Information.

\section{ASSOCIATED CONTENT}

\section{(5) Supporting Information}

The Supporting Information is available free of charge on the ACS Publications website at DOI: 10.1021/acschembio.8b00969.

Experimental procedures, supporting figures, supporting tables and compound characterization (PDF)

Data set of identified proteins in HepG2 cells, BAT and WAT (XLSX)

\section{AUTHOR INFORMATION}

\section{Corresponding Author}

*E-mail: m.van.der.stelt@chem.leidenuniv.nl.

ORCID $\odot$

Juan Zhou: 0000-0002-1181-7134

Elliot D. Mock: 0000-0002-1500-2856

Andrea Martella: 0000-0002-4680-7702

Vasudev Kantae: 0000-0001-8541-0882

Sebastian H. Grimm: 0000-0002-8832-8259

Mario van der Stelt: 0000-0002-1029-5717

Notes

The authors declare no competing financial interest.

\section{ACKNOWLEDGMENTS}

We thank the Chinese Scholarship Council (JZ, Grant No. 201207060003) for financial support. We thank N. Ueda for kindly providing the plasmids of the HRASLS family. We acknowledge ChemAxon for kindly providing the Instant JChem software to manage our compound library.

\section{REFERENCES}

(1) Hajnal, A., Klemenz, R., and Schäfer, R. (1994) Subtraction cloning of $\mathrm{H}-\mathrm{rev} 107$, a gene specifically expressed in $\mathrm{H}$-ras resistant fibroblasts. Oncogene 9, 479-490.

(2) Roder, K., Kim, K.-H., and Sul, H. S. (2002) Induction of murine H-rev107 gene expression by growth arrest and histone acetylation: involvement of an Sp1/Sp3-binding GC-box. Biochem. Biophys. Res. Commun. 294, 63-70.

(3) Sers, C., Emmenegger, U., Husmann, K., Bucher, K., Andres, A. C., and Schafer, R. (1997) Growth-inhibitory activity and downregulation of the class II tumor-suppressor gene H-rev107 in tumor cell lines and experimental tumors. J. Cell Biol. 136, 935-944.

(4) DiSepio, D., Ghosn, C., Eckert, R. L., Deucher, A., Robinson, N., Duvic, M., Chandraratna, R. A. S., and Nagpal, S. (1998) Identification and characterization of a retinoid-induced class II tumor suppressor growth regulatory gene. Proc. Natl. Acad. Sci. U. S. A. $95,14811-14815$.

(5) Wang, L., Yu, W., Ren, X., Lin, J., Jin, C., and Xia, B. (2012) $1 \mathrm{H}, 13 \mathrm{C}$, and $15 \mathrm{~N}$ resonance assignments of the $\mathrm{N}$-terminal domain of human TIG3. Biomol. NMR Assignments 6, 201-203.

(6) Golczak, M., Kiser, P. D., Sears, A. E., Lodowski, D. T., Blaner, W. S., and Palczewski, K. (2012) Structural basis for the acyltransferase activity of lecithin:retinol acyltransferase-like proteins. J. Biol. Chem. 287, 23790-23807.

(7) Golczak, M., Sears, A. E., Kiser, P. D., and Palczewski, K. (2015) LRAT-specific domain facilitates vitamin A metabolism by domain swapping in HRASLS3. Nat. Chem. Biol. 11, 26-32.

(8) Pang, X.-Y., Cao, J., Addington, L., Lovell, S., Battaile, K. P., Zhang, N., Rao, J. L. U. M., Dennis, E. A., and Moise, A. R. (2012) Structure/function relationships of adipose phospholipase A2 containing a Cys-His-His catalytic triad. J. Biol. Chem. 287, $35260-35274$.

(9) Ren, X. B., Lin, J. A., Jin, C. W., and Xia, B. (2010) Solution structure of the N-terminal catalytic domain of human H-REV107-A novel circular permutated NlpC/P60 domain. FEBS Lett. 584, $4222-4226$.

(10) Hsu, T. H., Chu, C. C., Jiang, S. Y., Hung, M. W., Ni, W. C., Lin, H. E., and Chang, T. C. (2012) Expression of the class II tumor suppressor gene RIG1 is directly regulated by p53 tumor suppressor in cancer cell lines. FEBS Lett. 586, 1287-1293.

(11) Roder, K., Latasa, M. J., and Sul, H. S. (2002) Silencing of the mouse H-rev107 gene encoding a class II tumor suppressor by CpG methylation. J. Biol. Chem. 277, 30543-30550.

(12) Hummasti, S., Hong, C., Bensinger, S. J., and Tontonoz, P. (2008) HRASLS3 is a PPAR gamma-selective target gene that promotes adipocyte differentiation. J. Lipid Res. 49, 2535-2544.

(13) Jin, X.-H., Uyama, T., Wang, J., Okamoto, Y., Tonai, T., and Ueda, N. (2009) cDNA cloning and characterization of human and mouse $\mathrm{Ca}^{2+}$-independent phosphatidylethanolamine $\mathrm{N}$-acyltransferases. Biochim. Biophys. Acta, Mol. Cell Biol. Lipids 1791, 32-38.

(14) Duncan, R. E., Sarkadi-Nagy, E., Jaworski, K., Ahmadian, M., and Sul, H. S. (2008) Identification and functional characterization of adipose-specific phospholipase a2 (AdPLA). J. Biol. Chem. 283, $25428-25436$.

(15) Uyama, T., Jin, X.-H., Tsuboi, K., Tonai, T., and Ueda, N. (2009) Characterization of the human tumor suppressors TIG3 and HRASLS2 as phospholipid-metabolizing enzymes. Biochim. Biophys. Acta, Mol. Cell Biol. Lipids 1791, 1114-1124.

(16) Jaworski, K., Ahmadian, M., Duncan, R. E., Sarkadi-Nagy, E., Varady, K. A., Hellerstein, M. K., Lee, H.-Y., Samuel, V. T., Shulman, G. I., Kim, K.-H., de Val, S., Kang, C., and Sul, H. S. (2009) AdPLA ablation increases lipolysis and prevents obesity induced by high-fat feeding or leptin deficiency. Nat. Med. 15, 159168.

(17) Elling, U., Wimmer, R. A., Leibbrandt, A., Burkard, T., Michlits, G., Leopoldi, A., Micheler, T., Abdeen, D., Zhuk, S., Aspalter, I. M., Handl, C., Liebergesell, J., Hubmann, M., Husa, A. M., Kinzer, M., Schuller, N., Wetzel, E., van de Loo, N., Martinez, J. A. Z., Estoppey, D., Riedl, R., Yang, F. T., Fu, B. Y., Dechat, T., Ivics, Z., Agu, C. A., Bell, O., Blaas, D., Gerhardt, H., Hoepfner, D., Stark, A., and Penninger, J. M. (2017) A reversible haploid mouse embryonic stem cell biobank resource for functional genomics. Nature 550, 114-118.

(18) Staring, J., von Castelmur, E., Blomen, V. A., van den Hengel, L. G., Brockmann, M., Baggen, J., Thibaut, H. J., Nieuwenhuis, J., Janssen, H., van Kuppeveld, F. J. M., Perrakis, A., Carette, J. E., and Brummelkamp, T. R. (2017) PLA2G16 represents a switch between entry and clearance of Picornaviridae. Nature 541, 412-416.

(19) Liu, Y. S., Patricelli, M. P., and Cravatt, B. F. (1999) Activitybased protein profiling: the serine hydrolases. Proc. Natl. Acad. Sci. U. S. A. 96, 14694-14699.

(20) Niphakis, M. J., and Cravatt, B. F. (2014) Enzyme inhibitor discovery by activity-based protein profiling. Annu. Rev. Biochem. 83, 341-377.

(21) Baggelaar, M. P., Janssen, F. J., van Esbroeck, A. C. M., den Dulk, H., Allara, M., Hoogendoorn, S., McGuire, R., Florea, B. I., Meeuwenoord, N., van den Elst, H., van der Marel, G. A., Brouwer, J., Di Marzo, V., Overkleeft, H. S., and van der Stelt, M. (2013) Development of an activity-based probe and in silico design reveal highly selective inhibitors for diacylglycerol lipase-alpha in brain. Angew. Chem., Int. Ed. 52, 12081-12085.

(22) Baggelaar, M. P., Chameau, P. J. P., Kantae, V., Hummel, J., Hsu, K. L., Janssen, F., van der Wel, T., Soethoudt, M., Deng, H., den Dulk, H., Allara, M., Florea, B. I., Di Marzo, V., Wadman, W. J., Kruse, C. G., Overkleeft, H. S., Hankemeier, T., Werkman, T. R., Cravatt, B. F., and van der Stelt, M. (2015) Highly selective, reversible inhibitor identified by comparative chemoproteomics modulates diacylglycerol lipase activity in neurons. J. Am. Chem. Soc. $137,8851-8857$. 
(23) van Esbroeck, A. C. M., Janssen, A. P. A., Cognetta, A. B., Ogasawara, D., Shpak, G., van der Kroeg, M., Kantae, V., Baggelaar, M. P., de Vrij, F. M. S., Deng, H., Allara, M., Fezza, F., Lin, Z., van der Wel, T., Soethoudt, M., Mock, E. D., den Dulk, H., Baak, I. L., Florea, B. I., Hendriks, G., de Petrocellis, L., Overkleeft, H. S., Hankemeier, T., De Zeeuw, C. I., Di Marzo, V., Maccarrone, M., Cravatt, B. F., Kushner, S. A., and van der Stelt, M. (2017) Activitybased protein profiling reveals off-target proteins of the FAAH inhibitor BIA 10-2474. Science 356, 1084-1087.

(24) Yang, P. Y., Liu, K., Ngai, M. H., Lear, M. J., Wenk, M. R., and Yao, S. Q. (2010) Activity-based proteome profiling of potential cellular targets of Orlistat - an FDA-approved drug with anti-tumor activities. J. Am. Chem. Soc. 132, 656-666.

(25) Uyama, T., Morishita, J., Jin, X. H., Okamoto, Y., Tsuboi, K., and Ueda, N. (2009) The tumor suppressor gene H-Rev107 functions as a novel $\mathrm{Ca}^{2+}$-independent cytosolic phospholipase $\mathrm{A}_{1 / 2}$ of the thiol hydrolase type. J. Lipid Res. 50, 685-693.

(26) Aoyagi, T., Nagai, M., Ogawa, K., Kojima, F., Okada, M., Ikeda, T., Hamada, M., and Takeuchi, T. (1991) Poststatin, a new inhibitor of prolyl endopeptidase, produced by Streptomycesviridochromogenes MH534-30F3. J. Antibiot. 44, 949-955.

(27) Fusetani, N., Matsunaga, S., Matsumoto, H., and Takebayashi, Y. (1990) Bioactive marine metabolites. 33. Cyclotheonamides, potent thrombin inhibitors, from a marine sponge Theonella sp. J. Am. Chem. Soc. 112, 7053-7054.

(28) Nakao, Y., Matsunaga, S., and Fusetani, N. (1995) Three more cyclotheonamides, $\mathrm{C}, \mathrm{D}$, and $\mathrm{E}$, potent thrombin inhibitors from the marine sponge Theonella swinhoei. Bioorg. Med. Chem. 3, $1115-1122$.

(29) Nakao, Y., Oku, N., Matsunaga, S., and Fusetani, N. (1998) Cyclotheonamides E2 and E3, new potent serine protease inhibitors from the marine sponge of the genus Theonella. J. Nat. Prod. 61, $667-670$.

(30) van Rooden, E. J., Florea, B. I., Deng, H., Baggelaar, M. P., van Esbroeck, A. C. M., Zhou, J., Overkleeft, H. S., and van der Stelt, M. (2018) Mapping in vivo target interaction profiles of covalent inhibitors using chemical proteomics with label-free quantification. Nat. Protoc. 13, 752-767.

(31) Tsai, F. M., Chen, M. L., Wang, L. K., and Lee, M. C. (2015) $\mathrm{H}$-rev107 regulates cytochrome $\mathrm{P} 450$ reductase activity and increases lipid accumulation. PLoS One 10, e0138586.

(32) Gibbons, G. F., Khurana, R., Odwell, A., and Seelaender, M. C. L. (1994) Lipid balance in HepG2 cells - active synthesis and impaired mobilization. J. Lipid Res. 35, 1801-1808.

(33) Park, J.-Y., Kim, Y., Im, J. A., and Lee, H. Oligonol suppresses lipid accumulation and improves insulin resistance in a palmitateinduced in HepG2 hepatocytes as a cellular steatosis model. BMC Complementary Altern. Med. 2015, 15, DOI: 10.1186/s12906-0150709-1.

(34) De Risi, C., Pollini, G. P., and Zanirato, V. (2016) Recent developments in general methodologies for the synthesis of $\alpha$ ketoamides. Chem. Rev. 116, 3241-3305.

(35) Yuan, W., Wong, C. H., Haeggstroem, J. Z., Wetterholm, A., and Samuelsson, B. (1992) Novel tight-binding inhibitors of leukotriene A4 hydrolase. J. Am. Chem. Soc. 114, 6552-6553.

(36) Patel, D., Gless, R. D., Hsu, H. W. K., Anandan, S. K., and Aavula, B. R. (Arete Therapeutics, Inc.) (2008) Soluble epoxide hydrolase inhibitors, U.S. PatentUS20080200467A1.

(37) Shen, H. C. (2010) Soluble epoxide hydrolase inhibitors: a patent review. Expert Opin. Ther. Pat. 20, 941-956.

(38) Ascione, A. (2012) Boceprevir in chronic hepatitis C infection: a perspective review. Ther. Adv. Chronic Dis. 3, 113-121.

(39) Butt, A. A., and Kanwal, F. (2012) Boceprevir and telaprevir in the management of hepatitis $\mathrm{C}$ virus-infected patients. Clin. Infect. Dis. 54, 96-104. 